\title{
Ritem in metrum
}

\author{
Vid Snoj
}

Filozofska fakulteta Univerze v Ljubljani, Oddelek za primerjalno književnost in literarno teorijo, Aškerčeva 2, 1000 Ljubljana

https://orcid.org/0000-0001-9128-9919

vid.snoj@guest.arnes.si

\begin{abstract}
Članek izhaja iz grškega razumevanja pesništva, ki je postalo norma v antiki in to ostalo tudi globoko v poantične čase. V skladu s tem razumevanjem je pesnjenje umerjanje oziroma spravljanje besed v mero ( $g r$. métron) in pesništvo umetnost metričnega vezanja govora ter s tem tvorjenja verzov, tj. verzifikacije. Zdi se, da je ritem v grško-rimskem pesništvu zajetv mero, ki je bila kvantitativna mera, trajanje zlogov. Vendar se je že v antični metriki začel ločevati od metra, čeprav mu je kot sistemski strukturi hkrati ostajal podrejen. Ko pa je razlika med dolgimi in kratkimi zlogi, na kateri je temeljil kvantitativni verzifikacijski sistem, v pozni antiki postala neslišna, se je začelo osvobajanje od metra v znamenju ritma. "Ritem "je v srednjem veku opisoval ustroj pesmi $v$ ljudskih jezikih poantične Evrope in se v renesansi uveljavil kot prvotna oznaka za silabični verzifikacijski sistem. Toda posnemanje metra se je v evropskem pesništvu nadaljevalo in demetrizacija izmenjavala z remetrizacijo. Zato moderna verzologija ponazarja razvoj evropske verzifikacije z gibanjem morskih valov, ki ni enakomerno kakorv naravi: metrum je v upadu in v naraščanju ves čas ritem. Vpodobi, ki jo naslika, dokončno osvoboditev ritma od metra predstavlja prosti verz. Kljub temu pa se članek na koncu vrne na začetek z opozorilom, da rhythmós prvotno ni meril na nič slišnega, ampak na zvečine vidno hipno obliko nečesa neobstojnega. Na tej podlagi nazadnje tudi poskuša opredeliti, kajje pesniški ritem.
\end{abstract}

Ključne besede: starogrška poetika / evropsko pesništvo / verzifikacija / metrum / ritem

Oddaljenemu p ogledu se ritem v grškem in, pozneje, tudi v rimskem pesništvu, ki se je ustrojilo po njem, kaže nekako zajet v metru (iz gr. métron, "mera«). ${ }^{1}$ Videti je, da je antični pesniški govor z metrom ali mero vezani, umerjeni govor, ki je postal tudi predmet posebne

\footnotetext{
${ }^{1}$ Razprava je nastala v okviru raziskovalnega programa P6-0239, ki ga je iz državnega proračuna sofinancirala Javna agencija za raziskovalno dejavnost Republike Slovenije. Prvi spis o ritmu in metru v slovenščini je leta 1917 objavil Oton Župančič v Ljubljanskem zvonu. Ta razprava se na Župančičev spis navezuje z naslovom, ki ga ponavlja z njim, sicer pa je širša po zajetju snovi in se od njega razlikuje tudi po tematskem fokusu.
} 
discipline, metrike, katere začetki segajo v klasično obdobje grštva. ${ }^{2}$ Toda »ritem« je beseda $\mathrm{z}$ več pomeni. V zgodovino grškega pesništva oziroma njegovega preučevanja je kmalu stopil $v$ enem izmed teh pomenov, kot nekaj, česar ni mogoče imeti za popoln metrum in kar se razločno, a nejasno odmika ter celo odstopa od njega. V zgodovini evropskega pesništva, ki od grštva naprej velja za umetnost vezanja besede ali tvorjenja verzov, verzifikacije, pa se je nazadnje uveljavil v pomenu nasprotja metru, kot osvobajanje od njega.

Zgodovina evropskega verza (in verzologije) se $\mathrm{v}$ grobem spleta $\mathrm{v}$ zgodbo o metru in ritmu, katere dinamiko narekujeta enkrat zavračanje, drugič spet posnemanje grško-rimske verzifikacije. Mihail Gasparov v svoji véliki sintezi o evropski verzifikaciji ugotavlja, da ima ta povrhu razvoj, ki "teče valovito" (Gasparov 236). Derek Attridge pravi nekaj takega tudi o zgodovini angleškega verza, namreč da je pogosto razumljena »kot vrsta valov v naraščajoči plimi«, ki so v resnici »zapovrstni valovi metričnega rahljanja" (Attridge 167). Spet nekaj podobnega bi bilo z verznozgodovinskega gledišča mogoče reči za verz $\mathrm{v}$ drugih poklasičnih evropskih jezikih. Verzologija zna razvoj evropske verzifikacije pogosto prikazati s podobo valovanja, $\mathrm{v}$ kateri se vračanje metra izmenjuje z dviganjem ritma. Lahko bi celo rekli, da je takšen razvoj glede na našo privajeno, stoletja staro predstavo o ritmu, v kateri ga povezujemo z gibanjem morskih valov (prim. Benveniste 352), sam ritmičen, vendar s pripombo, da je v tej podobi oseka venomer vračanje brez vrnitve nazaj in plima, kljub osekam, napredovanje: metrum se umika, na plimnem valu pa jezdi ritem.

Naj dolgo zgodbo povem na kratko in naj jo začnem z navadno, a globoko zakoreninjeno predstavo o pesništvu. Kadar dandanašnji, ko pesmi za razloček od svojih antičnih prednikov raje beremo kot poslušamo (oziroma jih poslušamo po tiho med branjem), zagledamo pred sabo besede, postavljene v vrstice, ki se, ne da bi na strani tekle od leve proti desni nepretrgano do konca, končujejo prej in so poleg tega bolj ali manj enake dolžine, kadar torej takšne vrstice, še preden jih preberemo od besede do besede, zajamemo s pogledom, pomislimo: to je pesem, opravka imamo s pesništvom. Naša prva pomisel, ne da bi nam bilo treba sploh kaj razmišljati, je: pesništvo je neko besedje v približno enako dolgih vrsticah, krajših od potiskljive širine strani.

To predstavo o pesništvu pravzaprav upoveduje že latinska beseda versus, "obrat", in sicer zgovorneje od grške stíchos, ki pomeni kratko malo "vrsto" ali "vrstico«. Versus izhaja iz glagola verto, "obrnem" ali

\footnotetext{
${ }^{2}$ Pregled antične metrike podaja Ulrich von Wilamowitz-Moellendorff (58-79).
} 
"obrnem se«, vendar ne tako, da bi šel stran, ampak tako, da pridem nazaj, se vrnem na začetek. Obrat, ki ga naredim, ni odvrnitev v to ali ono stran, ampak je zavrtljaj. Verz je torej turn, ki je return: vrstica, ki se obrne - in s tem vrne. $V$ grščini ima pomen takšnega obrata beseda za kitico, strophé.

Obračanja in vračanja vrstic v prozi ni. V njej spremljamo lomljenje vrstic, ki je povsem mehanično in ustreza formatu vsakokratnega materialnega nosilca, $s$ tem da je dolžina vrstice odvisna od velikosti strani in širine roba $\mathrm{v}$ knjigi. Vrstica $\mathrm{v}$ prozi načelno venomer teče naravnost naprej, zato so Rimljani prozni govor imenovali oratio prorsa, "govor naravnost«. Cicero v Govorniku pravi, da je pesnik od govornika »bolj vezan [astrictior] z verzom» (Cicero 354). V nasprotju s proznim govorom, ki se na materialnem nosilcu sicer lomi, a glede na svoj notranji pogon teče naravnost naprej v nedogled, je pesniški govor omejen, vezan z verzno mero, oratio astricta. Ker pa pesniška vrstica, ki se za razloček od prozne obrne in z obratom vrne, za nameček vsakič znova prinese umerjen govor, prav na to, namreč na samo mero verza - metrum -, meri poznejša baročna preoznačitev pesniškega govora $\mathrm{v}$ oratio ligata. Ta izraz govori, da je pesniški govor vezani, in sicer metrično vezani govor.

Grški pojem pesništva ni zajemal vse literature, kot jo razumemo dandanes, ampak samo govor v vezani obliki. V Platonovih dialogih naletimo na različne opredelitve pesništva, tisto pa, ki povzema široko sprejeto razumevanje te umetnosti med Grki in mu daje filozofsko utemeljitev, beremo v Simpoziju. Kot svečenica Diotima razlaga Sokratu, je poiesis $\mathrm{v}$ temelju ustvarjanje, ki mu pripada nič manj kot ontološko dostojanstvo, vendar je ime poiesis, "pesništvo«, v grškem jeziku pridržano samo za neki poseben del ustvarjanja:

"... veš, da je ustvarjanje [poíesis] nekaj obširnega, kajti vsak vzrok, ki kar koli vodi iz nebivajočega v bivajoče, je ustvarjanje, tako da so tudi vsa udejanjevanja, ki sodijo v področje veščin [téchnai], stvaritve [poiéseis] in njihovi izdelovalci [demiourgoí] so vsi ustvarjalci [poietai]."

»Res je, kar praviš."

»In vendar veš, « je dejala, »da jim ne pravimo ustvarjalci, ampak da imajo druga imena. Od vsega ustvarjanja je ločen en del, ki se ukvarja z muzično umetnostjo [mousiké] in (pesniškimi) merami, in ime celote se nanaša nanj. Samo ta del se imenuje ustvarjanje/pesništvo [poíesis) in tisti ljudje, ki imajo delež v temu delcu ustvarjanja, so ustvarjalci/pesniki [poietai].« $(205 \mathrm{~b}-\mathrm{c})^{3}$

${ }^{3}$ Glej Platon, Zbrana dela 1,515-516. Besede izvirnika vstavljam iz Plato, Symposium 186. 
Beseda poiesis tu spregovarja $\mathrm{v}$ dveh pomenih. $\mathrm{V}$ širšem pomenu se nanaša na vse veščine ali umetnosti oziroma na njihovo delo, na ustvarjanje kot privajanje v bivanje, $v$ ožjem pa meri na eno samo. To je tista umetnost, ki besedam navadne govorice daje mero in jih z umerjanjem spravlja v vezano obliko: pesništvo. Tudi besede, ki jih metrično veže pesnik, tudi verzi, ki jih s tem nareja, so nekaj, česar prej ni bilo in kar šele prek njega pride v bivanje. Pesništvo je pri Platonu v najožjem pomenu umetnost izdelovanja verzov, verzifikacija.

Ta opredelitev pesništva se ujema z zgodnejšo opredelitvijo sofista Gorgije, po kateri je pesništvo govor z metrično zgradbo ali preprosto, kot pravi sam v slavilnem govoru o Heleni, "govor, ki ima mero [lógos échon métron] «. ${ }^{4}$ Ker je Platon v svojih dialogih sicer nadaljeval Sokratovo filozofsko polemiko s sofistiko, ujemanje Platonove opredelitve z Gorgijevo še toliko bolj kaže na grško razumevanje pesništva. V nasprotju z obema, Gorgijo in Platonom, pa Aristotel na začetku Poetike trdi, da metrum ni prepoznavno znamenje pesništva: ljudje sicer "povezujejo mero s pesnjenjem«, vendar "nimata Homer in Empedokles razen mere nič skupnega " (1447b). ${ }^{5}$ Čeprav Empedokles rabi metrum kakor Homer, za Aristotela kljub temu ni pesnik, ampak je physiológos, "naravoslovec«. Čeprav je delo $O$ naravi (Perì phýseos), ki ga ima tu v mislih Aristotel, napisal v heksametrih, to delo, v katerem s štirimi počeli zgodnjih jonskih mislecev, zemljo, zrakom, ognjem in vodo, ter z dvema vzrokoma njihovega spreminjanja, ljubeznijo in sporom, razgrinja izvor, ustroj in tek vsega, kar biva, ni pesniško. Zakaj ne, če pa Empedokles to počne v verzu Homerjeve epike, herojskem heksametru?

Pesništvo za Aristotela ni nikakršno umerjanje besed v verze, nikakršno izdelovanje verzov. Tako kot že za Platona, še zlasti v Državi, je tudi zanj v temelju mímesis, "posnemanje« ali "prikazovanje«, vendar hkrati prikazovanje, ki z besedami ustvarja, proizvaja oziroma izdeluje nekaj drugega. To je razvidno predvsem iz njegove obravnave tragedije, ki jo je sam imel za kraljico pesniških zvrsti in ji je v Poetiki namenil daleč največ prostora.

Aristotel v tem delu, ki ga lahko imamo za prvo evropsko teorijo pesništva sploh, kot najpomembnejši sestavni del tragedije prepozna mýthos. Ta v pomenu, ki mu ga da, ni več stara zgodba o božjem in človeškem, ampak novo uzgodbenje oziroma preuzgodbenje te zgodbe. Stari mit je snov, novi pa nastane z obdelavo v starem mitu sporočenih

${ }^{4}$ Navedeno po poslovenjeni Diels-Kranzovi izdaji Fragmenti predsokratikov. V slovenskem prevodu Borisa Vezjaka je to "govor v stihih" (Diels in Kranz 109).

${ }^{5}$ Aristotle, Poetics 30. Prim. slovenski prevod, Aristoteles, Poetika 62. 
dejanj, ki iz njega izloči tisto, kar si je pri delovanju kakega človeka navzkriž. Tragiški mit je mimesis tês práxeos, "prikazovanje dejanja" (1450a), ${ }^{6}$ katerega končno delo so smiselno v celoto povezana dejanja ljudi, ki s svojo sovisnostjo razkrivajo njihove značaje. Vendar mit kot izdelujoči prikaz dejanja ni samo sestavni del tragedije. V njem se navsezadnje na odlikovan način razodeva generično bistvo celotnega pesništva (prim. Halliwell 105), ${ }^{7}$ ki se sicer znatno manj kakor v dramskem ali epskem kaže tudi v lirskem pesništvu, v katerem je prav tako navzoča, a ne da bi se razvila, mitska prvina.

Pesnik, pribije Aristotel, mora biti prej "ustvarjalec [poietés] zgodb kakor mer" (1451b), ${ }^{8}$ prej izdelovalec novih zgodb iz starih kakor umerjevalec besed ali stihotvorec, in Empedokles ni pesnik zato, ker v herojskem heksametru govori o dogajanju sveta brez dejanj mitskih herojev, skratka brez človeškega dejanja. To, da je pesništvo izdelovanje verzov, je samo mnenje ljudi. Pesništvo je navsezadnje izdelovanje dejanj. Kljub temu pa je v antiki (in pozneje) prevladalo razumevanje, ki je bilo za Aristotela samo ljudsko mnenje, namreč da na pesništvo naletimo povsod tam, kjer obstaja metrum - v verzih.

Grško razumevanje pesništva je postalo norma. Kakšen je torej metrum, grškemu pesništvu lastna mera?

V grškem verzu ali stihu jezik s svojo naravno stihijo stopa v mero, ki je kvantitativna mera, trajanje zloga. Primerjalna historična metrika oziroma verzologija, zasnovana na začetku 19. stoletja, je dognala, da je grški kvantitativni verz nastal iz indoevropskega silabičnega verza. Osnovna enota prvotne indoevropske verzifikacije je bil zlog. Število zlogov je bilo približno enako, s tem da njihova razporeditev ni bila določena glede na trajanje, kaj šele na naglas, ampak je obstajala samo močna težnja, da predzadnjo pozicijo v verzu zasedejo bodisi sami dolgi bodisi sami kratki zlogi (prim. Gasparov 12-13).

Takšen prvotni silabični verz z zgolj nakazanim kvantitativnim koncem je grški verz preobrazil z metrizacijo in regularizacijo, umerjenjem in upraviljenjem. Umeril ga je z utrditvijo kvantitet, časovnih vrednosti zlogov, se pravi z ustalitvijo dolžin in kračin. Umerjanje zlogov (in $s$ tem besed po dolžinah in kračinah) je potekalo od konca verza proti začetku. Merska enota je sčasoma v grški metriki postala stopica, sestav

${ }^{6}$ Aristotle, Poetics 48. Prim. slovenski prevod, Aristoteles, Poetika 70.

${ }^{7} \mathrm{Na}$ to, da je rodovni pojem pesništva pri Aristotelu določen prav s prikazovanjem dejanja, napotuje že njegova trditev z začetka Poetike, da "prikazovalci prikazujejo delujoče [mimoûntai hoi mimoúmenoi práttontas] « (1448a).

${ }^{8}$ Aristotle, Poetics 60. Prim. slovenski prevod, ki ima tu za mýthoi "mite« in za métra »verze» (Aristoteles, Poetika 76). 
dveh ali več dolžin in/ali kračin, ali tudi par stopic, dvostopičje (kot enota na primer $\mathrm{v}$ jambskem trimetru, verzu tragedije, ki obsega šest jambov, štejeta dva jamba). Vendar se je v grškem verzu na samem začetku vzpostavilo načelo dveh kračin za dolžino, ki ga je Antoine Meillet, vélika avtoriteta na področju indoevropeistike v 20. stoletju, opazil pri delu že v Homerjevem daktilskem heksametru in ga označil za "grško novost" (Meillet 57).

Ta novost, izenačitev dolžine $s$ kračinama $v$ trajanju, je bila izredno pomembna. Po eni strani je pomenila opustitev izosilabičnosti, enakega števila zlogov, kot osrednjega načela pri graditvi verza, po drugi pa je omogočila ne le zamenjavanje zlogov, ampak tudi stopic. $\mathrm{V}$ grškem verzu je namreč $\mathrm{z}$ roko $\mathrm{v}$ roki $\mathrm{z}$ umerjanjem šla težnja $\mathrm{k}$ enakomernemu izmenjavanju dolžin in kračin ter $s$ tem $\mathrm{k}$ pravilnosti. Ta težnja se je najprej uveljavila $\mathrm{v}$ jonski epiki in potem še $\mathrm{v}$ dorski zborski liriki, ki je ljubila simetrijo. Nasprotno ni umerjanje v eolski monodični liriki nikdar seglo $s$ konca verza povsem na začetek, ampak sta tam ostali dve poziciji, ki ju je lahko zasedel bodisi dolg bodisi kratek zlog. Zato je ta lirika, čeprav mlajša od Homerjevih epov, bolj vezana na indoevropsko dediščino.

Toda grški verz kljub težnji $\mathrm{k}$ pravilnosti ni zapadel $\mathrm{v}$ enoličnost. To, da bi se enakomerno izmenjavanje dolžin in kračin sprevrglo $\mathrm{v}$ drdravo mehaniko, je preprečevalo prav načelo dveh kračin za dolžino. Mehanična pravilnost, ki bi jo povzročilo vrstenje ene same ves čas iste stopice, bi ubila vsak ritem. Grški verz pa ni poznal samo ancipitov, z zlogovnim trajanjem nedoločenih pozicij, ki so zapolnljive bodisi z dolgimi bodisi $s$ kratkimi zlogi, in anaklaz, prestavitev oziroma zaobrnitev kvantitete (- U v U - in narobe), ampak ob takšnih znotrajstopčinih premenah tudi zamenjavo stopic samih - in upraviljenje $\mathrm{v}$ skladu $\mathrm{z}$ imenovanim načelom je zadelo stopično menjavo. Pravilo, ki so se ga glede heksametra, najstarejšega kvantitativnega metra, držali Homer in njegovi nasledniki, je na primer bilo, da se daktil (- UU) zamenjuje $s$ spondejem (--), ne pa, recimo, $\mathrm{z}$ anapestom (UU -), in to ne glede na njuno enakotrajnost. Prvotno nenapisana pravila so določala, $s$ katero drugo stopico se lahko v kakem metru menja kaka stopica.

O metru grškega in, pozneje, rimskega pesništva, ki je pod vplivom grškega metriziralo stari italski saturnijski verz, lahko na splošno rečemo, da je v mero zajet, z umerjenjem zlogov po trajanju urejen ritem. Vendar ritem kljub temu niti v antiki ni bil razumljen kot popolnoma enak metru. Že nekateri antični preučevalci verza so ga začeli povezovati s tistim odmikom od natančnega umerjenja zlogovne dolžine, ki sam po sebi ne dovoljuje vzpostavitve matematične sorazmernosti. 
Preučevalci so se $\mathrm{v}$ resnici razdelili $\mathrm{v}$ dva tabora, metrike in ritmike. $\mathrm{O}$ mnenju ritmikov, da je trajanje dolgega zloga $\mathrm{v}$ daktilu nedoločljivo, poroča Dionizij iz Halikarnasa v spisu $O$ sestavljanju besed: „Ritmiki pa pravijo, da je dolgi zlog v tej stopici krajši od popolne dolžine, in ga, ne da bi mogli povedati, za koliko, imenujejo 'nesorazmernega' [álogon]«? Po drugi strani je verjetno, da je bila večina pétega pesništva - lirskega za razloček od epskega grškega pesništva, ki se je recitiralo - zato "podajana v racionaliziranem ritmu " (West 25). Dandanes se domneva, da so bili v racionaliziranem oziroma usorazmerjenem ritmu, kot ga je ubiralo petje, dolgi zlogi usklajeni z notami, ki so imele dvakrat ali trikrat večjo časovno vrednost od not, s katerimi so bili izenačeni kratki zlogi.

Ritmiki pa niso poudarjali le razločne nejasnosti zlogovne dolžine, ampak so zagovarjali tudi zamenljivost stopic s (približno) enakim trajanjem brez omejitev. Ritem je tako postal več od odmika v nedoločljivost, kar zadeva trajanje zlogov. Postal je odstop v umerjenem govoru, ki hodi oziroma teče stopično, od pravilne menjave stopic.

Horacij v eni izmed svojih od o Pindarju pravi, da kakor divja gorska reka vali navzdol nove besede numerisque fertur / lege solutis, "in nosijo ga zakona / rešeni ritmi« (Horace 222). $Z$ »ritmi« pri tem meri na mogočni tok Pindarjevega govora, ki se ne ozira na menjavo stopic v skladu s pravili. Za »ritem « rabi besedo numerus, »število« ali »štetje«, prvotni prevedek za grški rhythmós v latinščini, ki ga je šele sčasoma spodrinila sposojenka iz grščine rhythmus (navadno je sicer ravno narobe, namreč tako, da sposojenko nadomesti drugemu jeziku lastna, po tuji skovana ali bolj ali manj srečno izbrana izvirna beseda). V resnici je rhythmós z numerus $\mathrm{v}$ latinščini najprej dobil neposrečen sinonim: že beseda sama, namesto da bi kazala na mero, določeno z zlogovnim trajanjem, in na urejeno, s pravili skladno menjavo stopic, daje izstopiti številu zlogov v vrstici, čeprav ritem, ki odstopa od metra, zato še ne pomeni prehoda (oziroma vrnitve) od metričnega verza $\mathrm{k}$ silabičnemu, v katerem umerjanje zlogov po trajanju ni več v veljavi. V ritmih se stopice kratko malo menjavajo mimo pravil oziroma brez reda. Prav v tem smislu Kvintilijan v Šoli govorništva trdi, da so metri in ritmi - numeri, ki jih sam sicer že izrecno enači z rhythmi, a jim v rabi daje prednost pred njimi - oboji iz stopic, umerjenih s trajanjem zlogov, le da »ritmi sestojijo [samo] iz časovne dolžine, metri pa tudi iz reda [numeri spatio temporum constant, metra etiam ordine].$^{10}$

${ }^{9}$ Glej Dionysius of Halicarnassus, On Composition 128.

${ }^{10}$ Glej Quintilianus 186; dodatek in poudarek sta moja. Prim. slovenski prevod, ki ima za spatium temporum "časovne enote« in za ordo "zaporedje» (Kvintilijan 698). 
Metrum so že v antiki prav tako iskali v Bibliji. V nekaterih bibličnih knjigah, na primer v Jobovi knjigi, Knjigi psalmov ali Knjigi pregovorov, so ga najdevali helenizirani Judje, ki so pisali v grščini, in za njimi kristjani z grško izobrazbo, ki so znali hebrejsko. $\mathrm{Na}$ iskanje metra v Bibliji je vplivalo grško razumevanje pesništva v pomenu umerjenega govora, čeprav staro semitsko pesništvo po modernih dognanjih ni pripadalo kvantitativnemu, ampak toničnemu verzifikacijskemu sistemu, ki temelji na umerjanju zlogov po naglasu. $\mathrm{V}$ pozni antiki je to iskanje povzel Hieronim, prevajalec krščanske Biblije iz obeh izvirnih jezikov v latinščino, čigar prevod se je postopno uveljavil kot editio vulgata, splošno razširjena in vse do reformacije edino rabljena izdaja Biblije na krščanskem Zahodu. V uvodu v Jobovo knjigo ob sklicevanju na svoje judovske in krščanske predhodnike, na Filona Aleksandrijskega in Jožefa Flavija ter na Origena in Evzebija iz Cezareje, pravi takole:

Pri Hebrejcih je govor od začetka knjige pa vse do Jobovih besed v prozi. Toda od besed, ko Job pravi (Job 3,3):

Naj izgine dan, ko sem bil rojen,

in noč, ko so rekli, spočet je bil človek,

pa do mesta pred koncem knjige, kjer je zapisano (Job 42,6):

Zato sam sebe grajam

in se kesam v prahu in pepelu,

so tu heksametrski verzi, ki tečejo v daktilih in spondejih ter zaradi lástnosti jezika [propter linguae idioma] pogosto prav tako vsebujejo druge stopice, ne $\mathrm{z}$ enakim [številom] zlogov, ampak z enakim trajanjem (non earumdem syllabarum, sed eorumdem temporum). Včasih se od vrstic, rešenih metričnega zakona, dobi tudi sladek in zvončkljajoč ritem [quoque rhythmus ipse dulcis et tinnulus fertur numeris lege metri solutis] ... ${ }^{11}$

Ne samo da Hieronim v besedah fertur numeris lege metri solutis dopolnjujoče citira Horacija o Pindarjevem pesniškem furorju oziroma metričnem besnenju, s tem da lex izrecno imenuje lex metri, "metrični zakon". Poleg tega tu rhythmus izstopi iz sinonimije z numerus: numeri so metričnega zakona rešene vrstice, ki dajejo ritem. Toda to spet in še zdaleč ne pomeni osamosvojitve ritma v nasprotje metru. Hieronim ugotavlja, da ritem v Jobovi knjigi, tako kot že pri Pindarju in Horaciju, nastaja povsod tam, kjer se daktili ne menjajo le s spondeji, ampak tudi z drugimi stopicami. O teh stopicah, ne da bi jih poimenoval, pravi, da so ne glede na to, koliko zlogov imajo, enakega trajanja $s$ heksametrskima stopicama. Čeprav torej ritmični tok prinaša kršitev metričnega zakona in prekoračitev glede na red, na pravilnost stopične

${ }^{11}$ Hieronim, »Praefatio« 1140. 
menjave, je ritem vendarle samo odstop od metra znotraj metra. Metrum mu po umerjanju z zlogovnim trajanjem ostaja nadrejen. Vrh tega je ta lastnost biblične metrike $\mathrm{v}$ Hieronimovih očeh utemeljena $\mathrm{v}$ vrhovih grške in rimske lirike, zato je njegovo pisanje postalo poglavitni vir spekulacije o obstoju metra v Bibliji na krščanskem Zahodu, ki se je ohranila vse tja $\mathrm{v}$ renesanso.

Razumevanje ritma v pomenu osvobajanja iz primeža metra se je pojavilo šele pozneje. $\mathrm{V}$ pozni antiki so dolžine in kračine prenehale biti slišne. Čeprav si moderni verzologi niso edini glede tega, v katerem stoletju, domnevajo, da se je to zgodilo zaradi prozodične spremembe, natančneje, zaradi spremembe naglasa. Ta je bil v grččini prvotno slišen $\mathrm{v}$ višini tona, ne da bi imel kako vlogo pri graditvi verza, ker pa se je po novem začel izkazovati v jakosti in trajanju, je razlika $v$ trajanju zlogov, na kateri je temeljil kvantitativni verz, postala nezaznavna (prim. West 162). V starih pesniških besedilih so dolžine in kračine v svoji izvorni metrično-muzikalni podobi onemele in spevnost pesniškega govora se je nepovrnljivo utišala.

Prav tako $\mathrm{v}$ pozni antiki so se namnožile sodbe o razliki med metrom in ritmom. Te sodbe je v zgodnjem srednjem veku merodajno povzel angleški benediktinec Beda Častitljivi, ki je slovel kot največji učenjak svojega časa na krščanskem Zahodu, v spisu $O$ metrični umetnosti: ritem je "sestavitev besed, ki ni umerjena z metričnim sistemom [metrica ratione], ampak je s štetjem zlogov [numero syllaborum] stehtana po sodbi ušes, kot so spevi ljudskih pesnikov «. ${ }^{12} \mathrm{Tu}$ se numerus pomenljivo pojavi $v$ opredelitvi ritma. Po tej opredelitvi ritem nastaja $s$ spravljanjem besed v mero, vendar brez metričnega lógosa ali ratio, brez sistema, ki bi ga bilo mogoče razbrati v umerjenju dolžin in kračin, ampak samo s štetjem zlogov, tako, da jih v vsakem verzu nanese enako (ali vsaj približno enako) število. Ritem ni brez vsake mere - čeprav to ni več kvantitativna mera, ne več trajanje, ampak število zlogov -, vendar je »brez razloga" oziroma extra rationis, "zunaj sistema« klasične metrike. Takšen ritem Beda opaža v pesmih, ki so v srednjem veku začele nastajati v ljudskih jezikih.

Razpuščanje metričnega sistema in vračanje $\mathrm{k}$ silabičnemu se je sicer začelo že v srednjeveškem grškem in latinskem »ritmičnem " pesništvu ter je vzporedno $\mathrm{z}$ njim potekalo in se nadaljevalo v pesništvu v ljudskih, zlasti romanskih jezikih poantične Evrope. Verzi, utemeljeni na štetju zlogov, so obveljali za »ritmične« v jezikih, ki se ravnajo po drugačni prozodiji, se pravi intonaciji, naglaševanju in izgovarjavi, kakor

\footnotetext{
${ }^{12}$ Beda Častitljivi, De arte 173.
} 
klasična grščina in latinščina. A ker je bila graditev verzov zgolj z enakim številom zlogov oslabljena, je dodatni gradnik postalo zvočno ujemanje verznih koncev, rima, ki je v pesništvo prišla iz proze. Ta se od takšnega ujemanja, od sozvočja besednih koncev, navadno postavljenega na konec povedi, ali homojotelevta, ki se $\mathrm{v}$ antični retorski prozi pojavlja poljubno pogosto oziroma dokler se ga "govornik ne naveliča" (Averincev 314), razlikuje samo po tem, da je v ne več kvantitativni verzifikaciji postala pravilo. Na tesno zvezo rime z ritmom ne nazadnje napotuje besedna sorodnost, v kateri se "rima« kaže kot popačenka ali skvarjenka (fr. rim, ang. rhyme, nem. Reim itn.) iz »ritma".

K uveljavitvi ritma nasproti metru pa je postopno prispevala tudi Biblija. Hebrejsko pesništvo je z metričnim izrazjem prvi začel opisovati Filon v 1. stoletju. Raba tega izrazja oziroma sploh sklicevanje na obstoj metra v Bibliji za prepoznavo pesništva v njej je vsekakor spričevalo normativnosti, ki jo je grško razumevanje te umetnosti doseglo že v antiki. Vendar je judovska navezava na grško predstavo o pesništvu imela še drug, zmagoslaven obraz. Helenizirani Judje so namreč že veliko pred Filonom začeli zatrjevati judovsko prvenstvo, tudi kar zadeva pesniško metriko. Izročilo Grkov samih, ki izhaja od Herodota, in sicer da njihova modrost prihaja iz Egipta, so povezali s tem, da se je v Egiptu mudil Abraham, prvi judovski očak ter prejemnik Božje obljube o ljudstvu, ki da bo izšlo iz njega, in o deželi, ki da jo bo to ljudstvo prejelo v dediščino. ${ }^{13}$ Abraham je bil po njihovi sodbi prótos heuretés, "prvi najditelj« in učitelj modrosti, in judovski postavodajalec Mojzes, ki je svoje ljudstvo več rodov pozneje popeljal iz egiptovske sužnosti spet nazaj v obljubljeno deželo, učitelj pevca Orfeja (prim. Hengel 165-167). Tako je za judovsko najdbo ob modrosti obveljal tudi metrum, ki naj bi ga Grki skupaj z modrostjo dobili od Judov v Egiptu. Razlago, da je Mojzes pred Platonom in Orfejem, ali celo, da je David (po izročilu avtor psalmov, ki nikdar ni bil v Egiptu) pred Homerjem, torej da sta grška filozofija in pesništvo judovskega izvora, so od njih pozneje prevzeli krščanski pisci.

Spet drugačna je bila razlaga srednjeveških judovskih komentatorjev Biblije. Po mnenju mnogih izmed njih je pesništvo starih Hebrejcev v obljubljeni deželi imelo metrum, a ga je izgubilo z izgnanstvom $\mathrm{v}$ Egiptu. Razlog za izgubo metra so videli prav v dolgotrajnem izgnanstvu. Vendar je z obžalovanjem izrekana teza o tej izgubi, ki je spet in spet napotovala na iskanje metra v Bibliji, dobila odmevno protitezo. Juda Halevi, po sodbi številnih poznavalcev največji judovski pesnik

${ }^{13} \mathrm{O}$ Abrahamu v Egiptu primerjaj $1 \mathrm{Mz}$ 12,10-13,1. 
pobibličnih časov sploh, v filozofskem dialogu Kuzari trdi, da so se biblični pisci namenoma izogibali rabi metra in da njegova odsotnost $\mathrm{v}$ Bibliji ni pomanjkljivost, ampak prednost. Za Halevija ni bilo nikakršne "nuje, da se v hebrejskih spevih najde kaka druga struktura (razen [te'amim], ki se ravnajo po 'pomenu')« (Kugel 191). Nasprotno: prednost bibličnega pesniškega načina je, da v besede s [te’amim], "naglasi«, prenaša tančine mišljenega, ne da bi izbiro besed narekovalo prilagajanje metru in bi se zaradi njega kalil pomen sporočila v pesniški besedi. Dolžina pesniških vrstic v Bibliji, priznava Halevi, je resda izrazito neenaka, vrstičje, ki ga v verze izgrajujejo pomenoprevodni naglasi, je nepesniško na oko. To je bilo v resnici očitno od mrtvomorskih rokopisov najprej, najstarejših ohranjenih rokopisih bibličnih knjig, v katerih se že pojavlja stihografija oziroma verzni zapis, s tem da hkrati vidno izpostavlja skladenjsko in pomensko, pa tudi zvočno ujemanje vrstičnih parov (ali polvrstic, ki sestavljata vrstico), ki je značilno za staro semitsko pesništvo na Bližnjem vzhodu, pozneje pa je dobilo oznako parallelismus membrorum, "paralelizem členov«, ali, prav zaradi prepoznavne navzočnosti v Bibliji, »biblični paralelizem«. Toda neenaka dolžina vrstic, pristavlja Halevi, se izravnava s petjem, ki nekatere zloge golta in druge razteguje.

Po drugi strani so se poantični krščanski komentatorji sklicevali na metrično hipotezo o Bibliji, kot jo je predvsem v uvodu k Jobovi knjigi ubesedil Hieronim. Na podlagi njegove trditve o obstoju enakotrajnih stopic, ki da se v tej knjigi ob spondejih menjavajo z daktili, so domnevali, da je bila prvotna hebrejska stopica drugačna od grške, še več, da je v Bibliji nekoč obstajal metrum na način sistema, ki zdaj ni več znan niti Judom. Od tod so sklepali, da biblični verz ni bil metričen na grško-rimski način, ampak podoben verzu pesmi, nastajajočih v barbarskih jezikih poantične Evrope. Tako je drugačnost biblične "metrike« od klasične omogočala uveljavljanje "ritmike«. Rhythmus je v srednjem veku opisoval ustroj pesmi v neklasičnih jezikih, v latinščini renesančnih učenjakov pa je začel »označevati posebno vrsto pesništva z rimami in enakim številom zlogov v vsaki vrstici« (Kugel 239). Postal je oznaka za pesniški red, ki se v temelju razlikuje od grško-rimskega, in $s$ tem prvotno poimenovanje za to, čemur dandanes s tehničnim izrazom pravimo »silabični verzifikacijski sistem".

Toda ritem v podobi razvoja, kot jo slika preučevanje evropske verzifikacije, ne prihaja šele za metrom. Če tu zdaj naredimo korak nazaj in v pogled zajamemo "širšo sliko", glede na to, da je pred metričnim verzom obstajal silabični verz in da se je ta $\mathrm{v}$ renesansi začel kratko malo imenovati »ritem«, ob neizogibni zameglitvi razlik med prvotno 
indoevropsko in poznejšo evropsko silabiko, ki jo s sabo prinaša takšen pogled, lahko rečemo, da je ritem tudi pred metrom. Poleg tega verznozgodovinska podoba od pojavitve metra naprej kaže valovanje, ki ga prispodoba morskega valovanja $\mathrm{z}$ enakomernim dnevno-nočnim naraščanjem in upadanjem ne izčrpa popolnoma. Ob vračanju metra se zmeraj znova vrača tudi ritem - in vrača se na valu napredka.

Rekonstrukcije skupnega indoevropskega verza so seveda hipotetične. Gasparov na hipotetičnost opozarja še zlasti v zvezi z grškim pesništvom, saj se v grškem verzu od prve, čiste silabične stopnje v nasprotju $\mathrm{z}$ indijskim verzom ni ohranilo nič (prim. Gasparov 48). Vendar teza, $s$ katero povzema rekonstrukcijske napore indoevropeistov, kljub temu stoji: metrum je že razcvet grške verzifikacije. Tudi z gledišča pesništva kot umetnosti izdelovanja verzov Homer ni začetek. Homerjeva rožnatoprstna zarja je vzšla izpod visoko vešče verzifikatorske roke.

Razvojna podoba evropske verzifikacije, ki jo razprostre Gasparov, je v osnovnih potezah tale: grški verz je za razloček od indijskega, ki je dosegel samo silabometrično stopnjo in nikdar čiste metrične, metriziral prvotni skupni indoevropski verz, metrizaciji je sledila resilabizacija grško-rimskega verza $\mathrm{v}$ romanskih jezikih ter resilabizaciji tonizacija silabičnosti v germanskih in slovanskih (ne pa tudi $v$ romanskih, ker ti pred pojavitvijo metra $v$ antiki niso poznali toničnega verza). Drugače rečeno: za umerjanjem zlogov po trajanju je (spet) prišlo umerjanje po številu in za tem, ob številu, še po naglasu. Silabotonični verzifikacijski sistem $\mathrm{v}$ primerjavi s silabičnim premore pomemben gradbeni dodatek: verz se $\mathrm{v}$ silabičnem sistemu vrača $\mathrm{z}$ bolj ali manj enakim številom zlogov, $v$ silabotoničnem pa z bolj ali manj enakim številom naglašenih in nenaglašenih zlogov.

Silabotonični verz je nastal z združitvijo romanskega silabičnega in starogermanskega toničnega aliteracijskega verza, s tem da je začetni soglasniški stik zamenjal končni samoglasniški in soglasniški stik, aliteracijo rima. Ta verz se je prvič pojavil v pesništvu Minnesängerjev nekje na prelomu 12 . in 13. stoletja ter se $\mathrm{z}$ avtoriteto verznega sistema dokončno uveljavil na začetku novega veka, v 17. stoletju. Silabotonika je zaradi močnejše, $\mathrm{z}$ naglaševanjem okrepljene graditve verza prevladala nad silabiko. Razširila se je skoraj po vsej Evropi, iz nemškega ne samo $\mathrm{v}$ angleško in pesništvo drugih germanskih narodov, ampak tudi $\mathrm{v}$ rusko pesništvo in pesništvo slovanskih narodov.

Pri tem pa se je v pesništvu po Evropi ves čas v valovih vračalo posnemanje metra. Demetrizacija klasičnega antičnega verza v grškem in latinskem "ritmičnem" pesništvu ter pesništvu v ljudskih jezikih je sprožila remetrizacijo že v srednjem veku, še preden je pripeljala do 
vzpostavitve novega verzifikacijskega sistema. Najmočnejši val posnemanja se je, spodbujen $\mathrm{z}$ italijanskim humanizmom, dvignil v renesansi in zajel pesništvo $\mathrm{v}$ vseh ljudskih jezikih, ki je stremelo $\mathrm{k}$ literarnemu omikanju teh jezikov. Toda poskus, da se poustvari antična kvantitativna stopica, je bil obsojen na neuspeh. Umerjanje besed po dolžinah in kračinah, ki niti v klasičnih jezikih niso bile več slišne, je bilo popolnoma arbitrarno in umetno opravilo. Uspeh je dosegla šele silabotonična stopica, vendar kot poustvaritev kvantitativne stopice $\mathrm{v}$ drugem verzifikacijskem sistemu, in sicer prek zamenjave zlogovne dolžine z naglasom. Kot je v svoji poetiki, prvi v nemščini, zapisal barokist Martin Opitz, ki je ob svojem času veljal tudi za največjega nemškega pesnika, ni tako, "da lahko na način Grkov in Latincev jemljemo v poštev določeno dolžino zlogov [eine gewiffe grôffe der fylben], temveč moramo iz akcentov in tona spoznavati, kateri zlog je treba postaviti visoko in katerega nizko", se pravi, kateri zlog je treba naglasiti in katerega ne, česar doslej ni dosledno upošteval "še nihče, niti jaz sam ne" (Opitz 38). Odtlej slišimo ritem grškega verza, a samo skoz naglas.

Posnemanje metra v nekvantitativnem verzifikacijskem sistemu se je nadaljevalo tudi v novem veku. Po drugi strani je osvobajanje od metra potekalo v znamenju ritma, ki se je pojavljal celo kot geslo proti takšnemu posnemanju in se na koncu dolgega izmenjavanja remetrizacije $\mathrm{z}$ demetrizacijo sprostil $\mathrm{v}$ tako imenovanem vers libre, "prostem verzu«. Ta mednarodni verz, v katerem nam verznozgodovinska podoba moderne verzologije daje videti dokončno osvoboditev ritma od metra (oziroma njegovega posnemanja v nekvantitativnem verzifikacijskem sistemu), se je razmahnil v vseh evropskih jezikih in je po Gasparovu zadnja stopnja, ki jo je v svojem razvoju dosegla evropska verzifikacija. Njegovi začetki v nemščini segajo v drugo polovico 18. stoletja $\mathrm{k}$ Friedrichu Gottliebu Klopstocku, v čigar freie Rhythmen sta opuščena tako posnemanje metra kakor tudi rima, in $\mathrm{v}$ angleščini $\mathrm{v}$ drugo polovico 19. stoletja $\mathrm{k}$ Waltu Whitmanu, ki je svoj verz oblikoval predvsem ob pomoči bibličnega paralelizma kot skladenjsko-pomensko-zvočnega sredstva. V 20. stoletju pa se je sintaktični prosti verz, v katerem se vrstica praviloma ujema s povedjo, razvezal $\mathrm{v}$ asintaktičnega, ki $\mathrm{v}$ vrsticah kontrapunktično ustavlja ali pohitruje navadni govorni tok, pogosto z opuščanjem ločil. Po sodbi Gasparova je takšno sproščanje besedne vezave v prostem verzu, ki se ne ravna več niti po skladenjskih enotah, hkrati tudi že uničevanje ritma, saj »občutenje razlik med ritmičnimi variacijami slabi ali izgine» (Gasparov 220).

Facit zgodbe, ki jo Gasparov, tako kot številni drugi moderni verzologi, začne $\mathrm{z}$ indoevropskim verzom in njegovo metrizacijo $\mathrm{v}$ grškem 
verzu, torej je: ritem, metrum, ritem. Vendar je na koncu ena od možnosti tudi uničenje ritma. Na koncu koncev je slepa ulica: opustitev verzne vrstice, raztresenje besed in, ob razpustitvi besed, celo razsutje črk po knjižni strani, ki smo mu priče v konkretni poeziji in letrizmu.

Ritem, metrum, ritem: zdi se, da se zgodba o ritmu in metru s tem konča. Treba pa je narediti še en korak nazaj. Kaj prvotno sploh je ritem?

Naša predstava, da je ritem $\mathrm{v}$ prvotnem pomenu gibanje morskih valov, je napačna. Kot v svoji besednoarheološki ekspertizi opozarja francoski jezikoslovec Émile Benveniste, grški samostalnik rhythmós izhaja iz glagola rheîn, "teči« - in ne teče morje, ampak reka. Vrh tega Grki s to besedo sploh niso označevali valovanja. Niso je rabili za tekočo vodo, "celo za 'ritem' ne« (Benveniste 353), če imamo pri tem namesto gibanja valov v mislih gibanje govora. Niti ritem ni bil v temelju nič slišnega (in s tem časnega).

Ravno narobe: rhythmós je v najstarejši rabi »oblika«, in sicer nečesa spremenljivega, tistega, kar v temelju ni (oziroma ni videti) trdno. Pri predsokratiku Demokritu je na primer vidna oblika, po kateri se zaradi različne razporeditve atomov razlikujeta zrak in voda, in pri lirikih oblika, ki jo poprime značaj kakega človeka. V nasprotju z drugimi grškimi besedami za »obliko", kot so schêma, morphé in eîdos, "označuje obliko v trenutku, ko je bila prevzeta od tistega, kar je gibljivo, gibajoče se, tekoče« (Benveniste 358). To je zvečine vidna hipna oblika nečesa, kar nima organske gostote ali trdnosti niti obstojnosti, oblika črke, kot se izpiše pri pisanju, obleke, kot se ta ali oni trenutek naguba pri nošenju, značaja ali celo razpoloženja, kot vznikne v človeški duši, a se lahko vsak trenutek spremeni. Benveniste poudarja, da je rhythmósu pomen »ritma« dal šele Platon. Ritem je pri njem postala oblika gibanja, ki jo zariše človeško telo. Še več: rhythmós je Platon povezal z mero in tako poimenoval urejeno gibanje telesa pri plesu (prim. npr. Fileb 17d), od tod pa se je ta beseda prenesla na takšno gibanje glasu in tonov v glasbi ter glasu in besed v pesništvu. Ritem je bil prej mera telesnega gibanja kot govora. Govorna mera je postal iz mere noge. ${ }^{14}$

${ }^{14} \mathrm{~V}$ zvezi s prenosom besede "ritem" na področje pesništva primerjaj odmevno tezo o plesnem izvoru daktilske stopice, ki jo je postavil Thrasybulos Georgiades v delu Der griechische Rhythmus. Musik, Reigen, Vers und Sprache (114-121). Po njegovem je bilo predvajanje Homerjevega epa prvotno skladno s stopanjem plesalcev v kolu (syrtós), tudi če ti niso plesali epa samega. Ta teza, po kateri je pevcu ritem dajal ples, se opira na notranji in zunanji dokaz: na osmi spev Odiseje, v katerem se Odisej mudi na otoku Fajakov in ti plešejo ob Demodokovem spevu (v. 246 isl.), ter na nepretrgan obstoj starega daktilsko umerjenega ritma od antike naprej, ki ga je ohranil syrtós kalamatianós, dandanes najbolj razširjen grški ljudski ples. 
In kaj je tedaj pesniški ritem? Lahko bi rekli, da je naravni ritem jezika oblika, ki v kateremkoli trenutku nastane v njegovem gibanju. Grosso modo so to vse oblike govorjenega jezika, vsaka (katerakoli) oblika, ki in kot se pojavi ter potem izgine, tudi vsaka v govorni stihiji ponovljena oblika, ki jo odnese njen tok. Pesniški ritem pa nastane $s$ ponovitvijo oblike - popolno ponovitvijo ali njeno variacijo -, ki obstane. Vstane, če uporabim Heglov diktum, s padcem oblike $v$ čas (prim. Vorlesungen 3,155 ) in je, kot pravi pesnik, "oblika, vrezana v ČAS « (Pound 198). Pesniški ritem je v ponovitvi dana in prepoznana oblika sredi govora, ki se giblje in tekoč spreminja $\mathrm{v}$ času.

Še enkrat: potrebna je ponovitev. Treba je, da se v besednem vzorčenju prepozna neki vzorec ali oblika kot to, kar se je vrnilo. Ponovitev je pogoj možnosti pesniškega ritma. Ta se umeri s ponovitvijo in teži $\mathrm{k}$ ponavljanju. $\mathrm{V}$ ponovitvi je že ritem in je mera. $\mathrm{V}$ njej ritem stopi $\mathrm{v}$ tako ali drugačno mero.

Pesniški ritem vznika tudi v prozi. Tam, kjer obstojne ponovitve ni, pa je stihija navadnega jezika, vrvež, gubanje oblik, nenehno obličenje, neskončna proza vsakdanjosti.

\section{LITERATURA}

Aristoteles. Poetika. Prevedel Kajetan Gantar. Ljubljana: Cankarjeva založba, 1982.

Aristotle. Poetics / Longinus. On the Sublime / Demetrius. On Style. Grški izvirniki z angleškim prevodom. Cambridge, MA: Harvard University Press, 2015 (Loeb 199).

Attridge, Derek. Poetic Rhythm. An Introduction. Cambridge: Cambridge University Press, 1996.

Averincev, Sergej. Poetika zgodnjebizantinske literature. Prevedel Pavle Rak v sodelovanju z Matejo Komel Snoj. Ljubljana: KUD Logos, 2005.

Beda Častitljivi. De arte metrica. Venerabilis Bedae, Anglo-saxonis presbyteri, opera omnia. Zv. 1. Izd. Jacques-Paul Migne in fratres Garnier, Pariz 1904 (PL 90). 149-175.

Benveniste, Émile. Problemi splošne lingvistike I. Prevedla Igor Žagar in Bernard Nežmah. Ljubljana: Založba ŠKUC in Znanstveni inštitut Filozofske fakultete, 1988.

Cicero. Brutus / Orator. Latinski izvirnik z angleškim prevodom. Cambridge, MA: Harvard University Press, 2014 (Loeb 342).

Diels, Hermann, in Walther Kranz. Fragmenti predsokratikov. 3 zv. Izd. Gorazd Kocijančič. Prevedli Dašo Benko idr. Ljubljana: Študentska založba, 2012.

Dionysius of Halicarnassus. Critical Essays I. On Literary Composition. Grški izvirnik z angleškim prevodom. Cambridge, MA: Harvard University Press, 2007 (Loeb 466).

Gasparov, Mihail Leonovič. Očerk istorii evropejskogo stiha. Moskva: Fortuna Limited, 2003 (2., dopolnjena izdaja).

Georgiades, Thrasybulos. Der griechische Rhythmus. Musik, Reigen, Vers und Sprache. Hamburg: Marion von Schröder Verlag, 1949.

Halliwell, Stephen. Aristotle's Poetics. London: Duckworth, 1998 (2. izd.). 
Hegel, Georg W. F. Vorlesungen über die Ästhetik I-III. Werke. Zv. 13-15. Izd. Eva Moldenhauer in Karl Markus Michel. Frankfurt na Majni: Suhrkamp, 1994 (4. izdaja).

Hengel, Martin. Judentum und Hellenismus. Studien zu ihrer Begegnung unter besonderer Berücksichtigung Palästinas bis zur Mitte des 2. Jahrhunderts v. Chr. Tübingen: J. C. B. Mohr (Paul Siebeck), 1969.

Hieronim. "Praefatio s. Hieronymi in librum Job". Sancti Eusebii Hieronymi Stridonensis presbyteri opera omnia. Zv. 9. Izd. Jacques-Paul Migne in fratres Garnier, Pariz 1890 (PL 28). 1138-1142.

Homer. Odiseja. Prevedel Anton Sovrè. Ljubljana: Založba Mihelač, 1991.

Horace. Odes and Epodes. Grški izvirnik z angleškim prevodom. Cambridge, MA: Harvard University Press, 2015 (Loeb 33).

Kugel, James L. The Idea of Biblical Poetry. Parallelism and Its History. Baltimore, London: The Johns Hopkins University Press, 1998.

Kvintilijan, Mark Fabij. Sola govorništva. Prevedel Matjaž Babič. Ljubljana: Zupančič\&Zupančič, 2015.

Meillet, Antoine. Les origines indo-européennes des mètres grecs. Pariz: Presses Univ. de France, 1923.

Opitz, Martin. Buch von der deutschen Poeterey (1624). Izd. Richard Alewyn. Tübingen: Niemeyer, 1963.

Plato. Lysis / Symposium / Gorgias. Grški izvirnik z angleškim prevodom. Cambridge, MA: Harvard University Press, 2015 (Loeb 166).

Platon. Simpozij. Zbrana dela. Zv. 1. Prevedel Gorazd Kocijančič, Celje: Mohorjeva družba, 2004. 74-91.

Platon. Fileb. Zbrana dela. Zv. 1. Prevedel Gorazd Kocijančič, Celje: Mohorjeva družba, 2004. 434-485.

Pound, Ezra. ABC of Reading. London, Boston: Faber and Faber, 1991.

Quintilianus, Marcus Fabius. The Orator's Education. Latinski izvirnik z angleškim prevodom. Cambridge, MA: Harvard University Press, 2014 (Loeb 124-127).

Sveto pismo stare in nove zaveze. Slovenski standardni prevod iz izvirnih jezikov. Ljubljana: Svetopisemska družba Slovenije, 1997 (2., pregledana izdaja).

West, Martin L. Greek Metre. Oxford: Clarendon Press, 1982.

von Wilamowitz-Moellendorff, Ulrich. Griechische Verskunst. Berlin: Weidmannsche Buchhandlung, 1921.

Župančič, Oton. »Ritem in metrum«. Ljubljanski zvon 37.5 (1917): 277-279. 


\section{Rhythm and Metre}

Keywords: ancient Greek poetics / European poetry / versification / metre / rhythm

The starting point of the paper is the Greek understanding of poetry, which became the norm in antiquity and has maintained such a status well into post-antiquity. According to this understanding, poetizing is a measuring or a putting of words into a measure (Gr. metron), while poetry is an art of metrical speech binding and thus of versification. The rhythm in Greco-Roman poetry seems to have been captured in a measure that was a quantitative measure, the duration of syllables. But already in ancient metrics rhythm began to separate from meter, although it remained subordinate to it as a systemic structure. When in late antiquity the distinction between long and short syllables, on which the quantitative system of versification was based, became inaudible, the liberation from the meter began under the sign of rhythm. "Rhythm" in Middle Ages described the structure of poems in the vulgar languages of post-antique Europe and established itself in the Renaissance as the primary term for the syllable versification system. However, the imitation of the meter continued in European poetry, with demetrification and remetrification alternating. Therefore, modern versiology illustrates the development of European versification with the movement of sea waves, which is not equable as in nature: the meter is in decline, while the rhythm is steadily increasing. In the picture it paints, the final liberation of rhythm from the meter is represented by the free verse. Nonetheless, at the end the paper returns to the beginning with the warning that rhythmos originally did not refer to something audible, but to the mostly visible momentary form of something unstable. On this basis it finally tries to define what a poetic rhythm is.

1.01 Izvirni znanstveni članek / Original scientific article

UDK 801.6

DOI: https://doi.org/10.3986/pkn.v44.i1.07 